\title{
Empresas familiares: desfilando seus processos sucessórios
}

\author{
Félix João Rossato Neto*
}

Neusa Rolita Cavedon*

\begin{abstract}
Resumo
O Mercado Público configura-se como uma instituição centenária que através da tradição vem mantendo uma posição diferenciada em relação aos demais centros de compra do gênero na capital gaúcha. A presente pesquisa busca identificar os aspectos que levam os filhos dos donos das lojas a darem continuidade ou não aos negócios de seus pais. 0 método etnográfico permitiu a vivência daquele cotidiano. Os resultados mostram que a primeira geração de empresários, descendentes de italianos, oriundos da zona rural do interior do Estado, estabeleceu uma rede. Aos homens, jovens, que optarem por não estudar, cabe-Ihes o "castigo" de começar desde tenra idade a sua socialização no ambiente onde os pais exercem suas atividades visando a sucessão. A filha mulher deve, preferencialmente, manter-se afastada do Mercado Público por ser esse um espaço predominantemente masculino Os atritos entre pais e filhos encontram ressonância nas diferenças geracionais decorrentes da ênfase ao "novo" dada pelos segundos e no apego ao "velho" defendido pelos primeiros.
\end{abstract}

Palavras-chave.: cultura organizacional, empresas familiares, processo sucessório.

\begin{abstract}
The Public Market has established itself as a centenary institution and through tradition has stood out among other retail oulets of the kind in the state's capital. The research aims at identifying the factors that lead shop-owners' descendants to succeeding or not their parents in business. The Ethnographic method allowed the acquaintance with that reality. The first generation of traders, that descend from Italian immigrants and came from rural areas in the countryside of the state, has established a network. Although formal education determines the pursuit of another carreer, the son is expected to take over from his father in business. Young male children who have quit school are supposed to start getting familiar with their parents' workplace at an early age so as to replace their progenitors later. Female children should preferably remain away from the Public Market because it is a male dominant environment. Their insertion only happens if they fail in their careers or become widowed or divorced. The conflicts between parents and children result from generation differences due to the emphasis placed on the "new" by the latter and the attachment to the "old" by the former.
\end{abstract}

Keywords: organizational culture, family enterprises, succession process.

\section{Introdução}

Os dramas humanos são universais e se manifestam de diversas formas em locais distintos. A relação entre pai e filho, por exemplo, pode ser encontrada ilustrando tanto uma obra artística - um quadro, um livro, uma música etc. - quanto configurada numa situação cotidiana - num almoço familiar, nas reuniões de uma empresa, ou mesmo evidenciada numa discussão em um momento de lazer -; enfim, em qualquer tempo e lugar, como ocorre no Mercado Público Central de Porto Alegre.

Segundo Gramkow e Cavedon (2001), o Mercado Público é um centro de compras, que reúne especiarias finas e artigos populares, com importante presença no desenvolvimento da capital gaúcha. Essa importância se deve

\footnotetext{
* Professor do Departamento de Ciências Administrativas da Escola de Administração da UFRGS. E-mail: felixneto@ terra.com.br.

** Professora e pesquisadora do PPGA do Departamento de Ciências Administrativas da Escola de Administração da UFRGS. E-mail: nrcavedon@ ea.ufrgs.br. 
ao fato de que o mercado não só é um ponto de abastecimento da cidade, um espaço para trocas econômicas, mas também um ponto turístico e espaço de cidadania.

Para Cavedon (2002), estudar o Mercado Público de Porto Alegre permite desvendar as especificidades do conhecimento administrativo atrelado aos aspectos locais. Nesse sentido, o Mercado Público pode ser enquadrado como uma organização local, cuja cultura organizacional revela aspectos não apenas da cultura porto-alegrense, mas também do estado do Rio Grande do Sul. Além disso, sendo gerido pelo poder público, apresenta a peculiaridade de contar com permissionários que podem ser caracterizados como "proprietários das bancas". Esses permissionários, por sua vez, submetem-se a um processo licitatório na prefeitura, para terem permissão de comercializar seus produtos naquele local. Normalmente, as bancas configuram-se como empresas familiares, e a prefeitura incentiva que as bancas passem de pai para filho, como forma de assegurar que a tradição histórica e familiar seja mantida. Essa tradição se manifesta no atendimento personalizado, na política de preços e na qualidade das mercadorias comercializadas.

Assim, esta pesquisa procura identificar quais os fatores que levam os filhos a sucederem seus pais nas bancas do Mercado Público. Como objetivos específicos destacam-se: identificar como os filhos dos permissionários assumem os negócios dos pais e como os permissionários preparam esse processo sucessório. Além disso, este estudo procura observar que fatores facilitam e quais criam entraves para as empresas familiares no processo de sucessão. Para isso, este estudo recorre ao suporte teórico da administração, da antropologia e da psicologia, valendo-se do método etnográfico. Vale destacar que, além da observação participante, foram realizadas 59 entrevistas que corresponderam a 51 bancas visitadas (em algumas bancas foram realizadas mais de uma entrevista). Considerando que o Mercado Público, segundo a Secretaria Municipal da Indústria e Comércio de Porto Alegre, tem 105 estabelecimentos comerciais, essas 51 bancas visitadas correspondem a 48,57\% desse universo.

Das 59 entrevistas, $25(42,37 \%)$ pertencem à primeira geração de permissionários, $30(50,85 \%)$ constituem a segunda geração e três $(5,08 \%)$ são da terceira geração. Uma entrevista $(1,69 \%)$ foi realizada com o empregado de uma banca na qual o proprietário se recusou a colaborar na pesquisa.

Diante disso, optamos por estruturar este artigo estabelecendo uma analogia com um desfile de modas, onde para compreender como as criações surgiram é preciso entender como o tecido foi escolhido e os alinhavos realizados (teorizações sobre empresa familiar e processo sucessório), bem como conhecer a costura e os arremates executados (dados e análise), para, finalmente, apresentarmos o desfile das criações (considerações finais).

\section{Empresa familiar}

\section{Escolhendo o tecido}

Não há consenso sobre o que seja uma empresa familiar. Enquanto alguns autores - dentre eles, Donnelley (1976) e Lodi (1993) - utilizam conceitos mais restritos, outros, como Leone (1991) e Longenecker (1997), usam conceitos mais amplos quanto ao que consideram ser uma empresa familiar, onde a presença ou não da segunda geração no negócio é a principal diferença.

Entre os estudiosos mais citados em livros e em artigos para se conceituar e/ou construir a definição de empresa familiar está Donnelley (1976). Para ele, a empresa somente pode ser considerada familiar quando é "perfeitamente identificada com uma família, pelo menos, há duas gerações e quando essa ligação resulta numa influência recíproca na política geral da firma e nos interesses e objetivos da família". (p.4)

Lodi (1993), da mesma forma que Donnelley (1976), ressalta a importância da segunda geração para o nascimento da empresa familiar, quando o fundador pretende abrir caminho para eles ou para os futuros sucessores. Ainda conforme Lodi (1993), a empresa familiar deve possuir valores institucionais que se identifiquem com um sobrenome de família ou com a figura do fundador. 
O conceito de Leone (1991, p.245), diferentemente dos autores citados anteriormente, é mais amplo, uma vez que não considera necessário que a segunda geração esteja presente na empresa e enfatiza as seguintes características: "iniciadas por um membro da família; membros da família participante da propriedade e/ou da direção; valores institucionais se identificando com um sobrenome de família ou com a figura do fundador; sucessão ligada ao fator hereditário". Nesse sentido, esse conceito congrega três grandes vertentes, no âmbito da propriedade, da gestão e da sucessão.

Nessa mesma linha teórica, de acordo com Longenecker (1997), a empresa familiar está implicitamente relacionada com a propriedade e o envolvimento de dois ou mais membros de uma família na existência e no funcionamento dessa empresa. Para ele, a natureza e a extensão desse envolvimento familiar é que variam.

Neste artigo, optou-se pelo conceito defendido por esses dois últimos autores, já que apresentam um espectro mais amplo na definição do que seja uma empresa familiar. Assim, pelo menos, duas vantagens são apontadas por Lanzana e Costanzi (1999) quanto ao uso desse critério (relação entre propriedade e controle) em comparação aos de Donnelley (1976) e Lodi (1993). A primeira é o fato de que muitas empresas não chegam à segunda geração e, além disso, não ficam dependendo da existência dessa geração como pré-requisito para serem consideradas empresas familiares. A outra vantagem é a de que a empresa necessita de um grau mínimo de concentração da propriedade do capital nas mãos de uma família; o suficiente para que esta tenha legitimidade para interferir no seu controle administrativo.

\section{Alinhavando o processo sucessório}

Na empresa familiar, como afirma Bernhoeft (1987, p.23), um dos aspectos de crucial importância é o "encaminhamento do processo sucessório, que passa a ter relação direta com a sobrevivência e a expansão do próprio negócio".

Para Leone (1992, p.85), sucessão é "o rito de transferência do poder e do capital entre a atual geração dirigente e a que virá a dirigir", podendo ocorrer de duas formas: "gradativa e planejada ou através de processo inesperado ou repentino de mudança de direção, quando ocorre morte, acidente ou doença, afastando o dirigente do cargo". Entretanto, na empresa, o poder não se transfere, ele é conquistado. A principal tarefa dos herdeiros é a construção de sua legitimidade perante os empregados e a família.

Além da transferência de poder e patrimônio, Tondo (1999) observa que a sucessão também envolve a transmissão de conhecimentos. Quanto à passagem do poder empresarial, a autora acrescenta que se trata de uma transferência entre adultos, mesmo que essas pessoas estejam vivendo fases diferentes da maturidade, já que os indivíduos adultos envolvidos nesse processo têm suas vidas condicionadas por perspectivas diferentes, têm idades distintas e estilos de vida diversos.

Segundo Grzybovski (2002), mesmo com a saída do fundador, o planejamento e a administração do negócio podem continuar sendo conduzidos de forma semelhante à estabelecida pelo primeiro dono, ainda que com enfoque alterado, seguindo estilo de liderança diferenciado e de acordo com formações teórica e prática renovadas. Por isso, o processo sucessório é um assunto relevante e delicado.

De acordo com Tondo (1999, p. 82):

Sucessão é um dos temas mais explorados da bibliografia especializada em empresas familiares. Há duas perspectivas básicas para explorar a noção de sucessão: como assunto isolado ou como uma parte do processo de desenvolvimento familiar e empresarial.

Para Vidigal (1999), cada vez mais, os estudiosos do assunto chegam à mesma conclusão: a questão da sucessão é o ponto-chave para o sucesso da empresa familiar.

Na opinião de Leone (1992), esse processo sucessório é uma situação natural que deverá ser enfrentada. A sucessão na empresa familiar torna-se problemática justamente por ser familiar. Existe uma expectativa dos 
dirigentes de que suas empresas continuem com a família, mais especificamente nas mãos de seus descendentes diretos. Ao fundador cabe a tarefa de despertar no sucessor o interesse pelo negócio da família.

Para Lodi (1994, p.41), antes de iniciar o processo sucessório, há que se considerar sete componentes de análise:

- os valores da família, ou seja, o código não escrito em torno do qual se desenvolveu a vida do fundador e que deveria unir as gerações maduras e vindouras;

- as relações de poder, ou seja, quem manda, quem segue e quem disputa a liderança;

- a ética interpessoal, ou o que é próprio e impróprio na relação com o patrimônio coletivo, com as pessoas, com as retiradas, com os negócios paralelos e com os conflitos de interesse;

- o dado comportamental que determina o padrão de interações psicológicas, as decisões, a motivação e a satisfação tanto pessoal quanto coletiva;

- os interesses patrimoniais, as preferências quanto à distribuição de resultados, a posses de ativos, a previsão de inventário e a doação de ações;

- o acesso à competência profissional que abre caminho para a auto-suficiência econômica e para a projeção profissional ou negocial na sociedade; e

- a instrumentação jurídica.

Segundo Bernhoeft (1987), os elementos constitutivos do processo de sucessão são: o sucedido, os potenciais sucessores, a família, a empresa, o mercado e a comunidade. Cada um desses setores tem interesses especiais na sucessão e, por assim ser, procuram atender preferencialmente àquilo que lhes afeta particularmente. A família mostra-se apreensiva ao observar o desgaste que se produz na luta pelo poder. A empresa sente o momento crítico e o potencial perigo para sua estabilidade. O mercado acompanha, igualmente apreensivo, o processo e suas implicações, sabendo que um eventual insucesso pode pôr em risco o futuro de muitos. A comunidade também assiste com expectativa a uma eventual mudança cultural que esse processo possa implicar.

No caso específico do Mercado Público, há outra interferência, que é a do poder público, o qual concede ou não permissão para o comerciante se estabelecer no local. Existem certas regras, previamente determinadas, a que os donos dos estabelecimentos precisam obedecer, seja em relação aos produtos ou serviços, seja quanto ao tamanho das bancas. $\mathrm{O}$ vínculo que se estabelece entre a prefeitura e o comerciante é, do ponto de vista jurídico, uma concessão, a título precário, pelo prazo de 10 anos; podendo ser prorrogada por igual período, sucessivas vezes, a critério do município.

No Edital de Concorrência nº 03/2001 da Secretaria Municipal da Produção, Indústria e Comércio (SMIC) de Porto Alegre consta a exigência de que no contrato social entre a prefeitura e o permissionário deve ter, obrigatoriamente, a seguinte cláusula:

No caso de morte ou impedimento de um dos sócios, a sociedade não sofrerá solução de continuidade, podendo os herdeiros constituir sociedade com os sócios remanescentes ou optarem pelo recebimento de seus haveres.

Segundo Barbieri (1997), os herdeiros são classificados conforme disposição de lei, tendo direito ao espólio, independentemente da vontade do testador. Existe o que se chama de ordem de vocação hereditária, que define a ordem de preferência dos herdeiros quanto ao espólio. Essa ordem é excludente, ou seja, na existência dos primeiros da relação, os demais são excluídos.

$\mathrm{Na}$ ordem legal (art. 1.603 do Código Civil Brasileiro) vigente até o final de 2002, a lei sobre sucessão determinava que, primeiro, era preciso separar a parte do cônjuge sobrevivente, que variava conforme o regime de casamento; depois, metade dos bens era destinada obrigatoriamente aos parentes nomeados pelo Código Civil, denominados herdeiros necessários. Pelo código válido até o final de 2002, segundo Barbieri (1997, p.15), metade da herança do sucedido deveria ser distribuída na seguinte ordem: 
- descendentes : filhos, netos e bisnetos;

- ascendentes: pai, avô e bisavô;

- cônjuge sobrevivente;

- colaterais: irmão e primos;

- município, Distrito Federal ou a União.

Tanaami (2002) observa que no novo código - em vigor a partir de 2003 -, a companheira ou companheiro, que antes era o terceiro na linha sucessória, passa a dividir a primeira fila com os filhos. Isso só vale se o casamento for em regime de separação total ou comunhão parcial de bens e não haja bens anteriores ao casamento. Se o casamento for no antigo regime de comunhão universal de bens ou se a comunhão for parcial com bens anteriores à união, o cônjuge entra na segunda linha, junto com os ascendentes. Essa mudança sutil terá uma conseqüência importante: antes, era mais fácil deixar o comando para o filho com mais aptidão para o exercício do negócio.

Floriani e Rodrigues (2000) consideram que hoje em dia parece muito mais raro do que no passado os filhos seguirem os passos do progenitor. Vidigal (1999), ao observar indústrias implantadas no começo do século passado, constatou que poucas sobreviveram. Ao olhar para as empresas criadas nas décadas de 1940 e 1950 , verificou uma grande quantidade de processos sucessórios mal encaminhados, levando a conflitos divulgados amplamente pela imprensa, e que, às vezes, culminaram com a venda da empresa. Em muitos casos, ou em quase todos, essas brigas poderiam ter sido evitadas, se o fundador (ou controlador) não tivesse se comportado como se fosse eterno, evitando pensar ou falar na sucessão.

Para Carrão (1997), a maior dificuldade do processo sucessório ocorre na passagem da primeira para a segunda geração. Prova disso é que 70\% das empresas familiares vivem, em média, 24 anos, tempo em que o fundador permanece na direção dos negócios. A primeira transferência guarda algumas características que não se repetem nas demais. $\mathrm{O}$ fundador tem uma relação afetiva muito profunda com a empresa que, para ele tem o sabor de prêmio pelas suas renúncias. O êxito nos negócios deve-se à sua habilidade, sua intuição, sua capacidade e dedicação ao trabalho. Para perpetuar seu projeto, o fundador acredita ser necessário que seus filhos entrem para a empresa.

Lodi (1994) escreve como um empreendedor foi sentenciado por sua pouca dedicação à vida familiar: "especializou-se no papel de homem de negócios, a ponto de não ter outros papéis na vida".

$\mathrm{Na}$ visão de Amat (2000), se, de um lado, estão os fundadores que demonstraram ter uma excelente visão comercial para identificar as necessidades do mercado e uma notável capacidade empreendedora para arriscar, de outro lado, estão os filhos desses fundadores que, em muitos casos, têm perfis mais profissionalizados que seus pais e que dificilmente se identificam com a organização que herdaram. Além disso, em muitas ocasiões, os sucessores não podem ter autonomia ou capacidade para fazer as mudanças estratégicas e organizacionais necessárias para renovar a empresa familiar.

Grzybovski (2002) acrescenta que enquanto o fundador é mais identificado com uma figura pouco profissionalizada, um empreendedor, o filho, seu sucessor, está marcado por uma identidade mais empresarial, mais profissional, flexível e descentralizadora.

Para Morgan (1996), organizações são estruturas que sobrevivem por gerações e nas quais o fundador, por identificação, encontra significado e permanência, fazendo dos seus papéis na empresa a sua realidade de vida, concretizados pelos produtos que fabrica e pelo retorno financeiro. Por essas razões, não é de admirar que as questões de sobrevivência sejam uma prioridade tão grande nas organizações, uma vez que aquilo que está em jogo é muito mais do que a simples sobrevivência da organização.

De acordo com Lodi (1994), o fundador cria uma empresa a partir de um sonho pessoal e chega ao fim da vida com dificuldades em compartilhar os seus valores com a segunda geração. O tecido dos sonhos da segunda geração precisa ser produto do trabalho de todas as pessoas envolvidas. Alguns fracassam porque não 
conseguem transpor a clausura de sua individualidade e transformar o seu sonho no projeto da segunda geração. Na opinião de Lodi (1986), a geração do fundador da empresa é, quando muito, pessoal e não-familiar. Dessa forma, os seus filhos precisam de uma crença que justifique sua ascensão ao poder.

Como se constata, algumas das dificuldades da empresa familiar começam com o fundador. Para Levinson (1977, p.3), em geral, o fundador é um empreendedor para o qual o negócio tem pelo menos três significados importantes:

- é característico do tipo empreendedor ter conflitos não resolvidos com seu pai, conforme mostram resultados de pesquisas. Por isso, ele não se sente à vontade quando está sendo supervisionado e inicia seu próprio negócio tanto para superar seu pai como para escapar à autoridade e à rivalidade de figuras mais poderosas;

- o negócio de um tipo empreendedor é ao mesmo tempo seu "filhinho querido" e sua "amante". É característico o fato de que aqueles que trabalham para ele sejam seus instrumentos na modelagem da organização. Se entre eles qualquer um aspirar a ser outra coisa que não seja um instrumento para o fundador - isto é, se quiser poder -, é provável que logo esteja na rua como mero espectador. Essa é a razão por que tantas organizações entram em decadência quando seus fundadores envelhecem ou morrem;

- para o empreendedor, o negócio é essencialmente uma extensão de si mesmo e sobretudo um meio de satisfação e realização pessoal. E se ele se preocupa com o que acontecerá com sua firma quando falecer, essa preocupação $\mathrm{cm}$ geral toma a forma do tipo de monumento que deixará.

Para Grzybovski (2002, p.164), o empreendedor tem um papel vital na empresa familiar:

(...) constata-se que o pilar da empresa é o empreendedor; a estrutura é formada pelo produto e pelo mercado (a grande oportunidade descoberta); os empregados (stakeholders internos) e a família (stakeholders externos) são os sujeitos que se sentem protegidos. Enquanto o empreendedor (pilar de sustentação) estiver presente, sabe-se que o vento, a chuva, o frio, a tempestade (...) não se farão presentes. Com sua perspicácia, capacidade adaptativa às constantes mudanças e situações, criatividade, flexibilidade nas tomadas de decisões, ele pode manter a família livre de qualquer "intempérie", ou seja, ele transforma a empresa (através da sua pessoa) em uma zona de segurança para a família.

Uma questão básica que envolve a família de empreendedores refere-se à carreira dos filhos. A tendência natural é pressionar o filho para que escolha a mesma carreira do pai; preferencialmente, que o primeiro parta do ponto em que o segundo parou. É a busca pela perpetuidade familiar. É também a demonstração de poder do pai sobre o filho, que demonstra, ao aceitar o encargo, buscar também o carinho perdido na infância em favor do irmão mais novo.

Quando o empreendedor, segundo Grzybovski (2002, p.131) "prepara seu sucessor; é comum que desenvolva nesse substituto traços de sua imagem e semelhança, socializando-o em seu mundo".

Lodi (1994) comenta que, se houve um comprometimento do fundador ao criar o negócio, a mesma coisa não foi pedida à segunda geração. Muitos estão no negócio pelo dinheiro e pela obrigação, não pelo comprometimento. Algumas pessoas trabalham por que têm que trabalhar, não porque querem trabalhar. Esse é o início da morte das empresas de família: os valores estão obscuros, as lealdades divididas e a motivação é baseada no dinheiro. O plano de sucessão do negócio familiar depende do tipo de comprometimento das pessoas e da capacidade de transmiti-lo.

Para Leone (1992), é importante o desejo de que um ou mais filhos continue o negócio familiar, ou, na falta deles, outro membro da família. Existe um verdadeiro apego sentimental do dirigente ao seu negócio. Eles não consideram a empresa como um simples bem que podem ceder após terem maximizado seu valor. Lodi (1993, p.21) acrescenta que "o êxito de um programa sucessório depende da maneira como o pai, que também preside a empresa, preparou sua família para o poder e a riqueza". 
Para Scheffer (1995), o questionamento das dificuldades envolvendo o momento da transferência de liderança, com o exame do que será melhor para a empresa, facilitará a gradual separação entre os sistemas empresarial e familiar, uma das fontes de conflito.

Segundo Longenecker (1997), os estágios do processo sucessório são os seguintes:

- estágio I ou pré-empresarial: não há planejamento formal na preparação da criança nesse período, quando ela pode ter apenas quatro ou cinco anos de idade, sendo um preparo para a próxima etapa;

- estágio II ou introdutório: difere do estágio I, no sentido de que os membros da família apresentam deliberadamente a criança para certas pessoas, associadas direta ou indiretamente à empresa, e lhe mostram outros aspectos relacionados aos negócios;

- estágio III ou funcional introdutório: o filho começa a trabalhar como empregado em tempo parcial. Isso ocorre freqüentemente durante períodos de férias, ou diariamente, depois das aulas. Nessa fase, o filho passa a conhecer alguns indivíduos-chave empregados na empresa. $\mathrm{O}$ estágio funcional introdutório inclui a preparação educacional e a experiência que o filho ganha em outras organizações;

- estágio IV ou funcional: começa quando o sucessor assume o emprego em tempo integral, após concluir sua formação educacional. Antes de passar a um posto gerencial, o sucessor pode trabalhar como contador, vendedor ou funcionário do estoque e possivelmente adquirir experiência em diversas outras funções;

- estágio V ou funcional avançado: ocorre quando o sucessor assume tarefas de supervisão, envolvendo a direção do trabalho dos empregados, mas não a administração-geral da empresa;

- estágio VI ou de sucessão: nesse estágio o filho é nomeado presidente ou gerente geral dos negócios. Nesse ponto, ele exerce, presumivelmente, a direção-geral dos negócios, mas o pai ainda está lhe dando apoio. O sucessor não dominou, necessariamente, as complexidades da presidência, e o predecessor pode estar relutante em abrir mão de todas as decisões;

- estágio VII ou maduro de sucessão: é atingido quando o processo de transição se completou, e o sucessor é tanto líder de fato quanto nominalmente. Em alguns casos, isso não ocorre até que o predecessor morra.

Para Leone (1992), a condição dos herdeiros em adquirir conhecimentos necessários ao negócio deve se dar ao lado do dirigente. Geralmente a preparação dos sucessores acontece na própria empresa, recebendo os conhecimentos necessários do negócio ao lado dos dirigentes. Os sucedidos, se não estão revelando muito interesse em procurar profissionais externos para assumir a direção do negócio, pelo menos, estão preocupados em formar e treinar seus sucessores para assumir esses postos com conhecimento de causa, ou seja, de pai para filho, durante muito tempo.

Scheffer (1995) observou que os sucessores, quando comparados aos sucedidos, apresentam formação acadêmica mais sólida. Em decorrência, pode-se dizer que surgem diferenças entre eles no estilo gerencial, fazendo com que a experiência de um e a formação de outro passem a representar fonte de discórdias.

Para Vidigal (1999), o fundador que consegue dar uma boa formação aos filhos, ter a lucidez necessária para perceber que não é imortal e resolver a sua sucessão enquanto está no comando da situação - evitando que os filhos se digladiem depois de sua morte - pode contar com a quase certeza de perpetuar a sua grande obra, que é a empresa que criou e fez crescer. Freqüentemente, o fundador tem medo de enfrentar a terrível realidade de que todos vamos morrer um dia. Porém, se não enfrentar isso, a família acabará entrando em conflito e a empresa acabará quebrando ou sendo vendida.

Segundo Levinson (1977), os empresários que ocupam o cargo por muito tempo sofrem pressão para perpetuar as organizações através da escolha de seus sucessores, mas, ao mesmo tempo, desejam demonstrar que ninguém é capaz de sucedê-los com a mesma competência. Para o autor, é um desejo inconsciente de preservar a onipotência e a imortalidade.

Para Leone (1991, p.247), a condição para organizar a sucessão constitui um longo percurso em que o dirigente torna-se um verdadeiro combatente, devendo percorrer as seguintes etapas: 
- $1^{\text {a }}$ etapa: o regime de casamento e a redação do testamento;

- $2^{\mathrm{a}}$ etapa: a valorização dos bens;

- $3^{\text {a }}$ etapa: encontrar a solução adequada, isto é, as medidas de caráter societário (a criação de uma holding para controle do grupo, a transferência de ações, manter entendimentos entre os grupos acionários ou fazer doação) ou alterações societárias como a cisão de empresas, fusões ou aquisição de ações.

As duas primeiras etapas do percurso equivalem às medidas necessárias à transmissão do capital. A terceira etapa corresponde à transmissão do poder.

Segundo Scheffer (1995), o processo sucessório não tem planejamento devido à recusa da idéia da morte e ao medo da perda do poder do sucedido. Outras razões apresentadas são o desejo do sucedido em deixar um legado seu e o temor de que seu sucessor possa desrespeitá-lo ou destruir o que foi construído durante anos.

Carrão (1997) propõe algumas questões que podem ser pensadas, para se avaliar qual é a melhor forma de sucessão. Por exemplo: qual será o papel do filho na empresa? Qual deverá ser seu relacionamento com os empregados antigos e leais? Qual será seu desempenho? Quais os critérios para distribuição das ações entre os herdeiros? Estas são questões relevantes para se planejar a sucessão. O assunto, segundo a mesma autora, deve ser discutido com os filhos, para que os conflitos inerentes ao processo sejam minimizados.

Para Leone (1992), a forma utilizada ou aconselhada como tratamento diante de conflitos no processo sucessório tem sido a profissionalização da empresa familiar, com a contratação de profissionais altamente qualificados ou indivíduos de renome comprovado para ocuparem cargos de direção na empresa.

\section{Costurando as composições entre os membros da família e fazendo os arremates}

\section{As famílias}

Uma das características dos permissionários das bancas do Mercado Público é que suas famílias são originadas do continente europeu, principalmente da Itália e de Portugal. Os permissionários italianos - grande parte destes, filhos e/ou netos dos imigrantes - são oriundos das colônias do interior do Rio Grande do Sul, onde suas famílias se estabeleceram. Quanto aos permissionários de origem portuguesa, estes saíram diretamente de sua terra natal para Porto Alegre. Os permissionários de origem italiana, pelo seu maior número, são o foco de um estudo mais amplo nesta pesquisa. Para Grzybovski (2002), a colonização no Rio Grande do Sul se caracterizou pela grande quantidade de imigrantes italianos, possuidores de traços e de desejo empreendedores, moldados num modelo de gestão em que prevalece a figura masculina. $\mathrm{O}$ caráter empreendedor do imigrante, como observa Maciel (1994), fez com que, mesmo desprezados na serra e nas matas, eles conseguissem oferecer uma perspectiva diferente ao estado, ao desenvolver setores importantes da economia regional. Para Maciel (1994), no Rio Grande do Sul, além do acesso à propriedade da terra, foi possível aos imigrantes adquirir outros bens materiais e simbólicos que não poderiam ter em seus países de origem. Com a ascensão social desses imigrantes, o termo colono, utilizado para denominá-los, deixou de ser "estigmatizador" tornando-se "enaltecedor". As áreas coloniais passaram a ter cada vez mais peso e os descendentes de imigrantes começaram a ter acesso ao poder.

Tendo em vista que a origem de muitos permissionários do Mercado Público, referida por eles mesmos, é a colônia, torna-se importante esclarecer que, segundo Woortmann (1995), a palavra colônia tem dois sentidos: o local em que o trabalho familiar é realizado e a região ocupada pelo imigrante e seus descendentes. Tanto em um caso quanto em outro, o significado do termo refere-se à família e ao trabalho.

Na visão de Oliven (1992, p.3), a migração do trabalhador rural ocorre "como uma tentativa de melhorar de vida". Os motivos que induzem a migrar e as expectativas em relação às cidades estão juntos. Para Durhan (1984), a migração e o projeto de ascensão social presentes são empreendimentos familiais.

Entender a colonização no Rio Grande do Sul e os aspectos relacionados às características dos gaúchos e dos imigrantes é importante, na medida em que muitos dos filhos desses imigrantes trabalham no Mercado Público. 
Após o pai ou o avô chegarem da Itália, os filhos e/ou netos descendentes migraram da colônia e seguiram para Porto Alegre. Deixaram a atividade rural do interior para tentar trabalho em um centro urbano; no caso, o Mercado Público de Porto Alegre.

\section{A sucessão}

Nessa pesquisa foram descobertas redes de parentesco entre os permissionários do mercado. Foi observado que uma dessas redes tinha pouco mais de um terço dos informantes com vínculos familiares; na sua grande maioria, descendentes de italianos vindos da colônia. Ainda junto a esses informantes foram obtidas informações adicionais sobre outras famílias e outras bancas. Um informante foi fundamental para o entendimento dessa intrincada rede. Por ser um dos permissionários mais antigos do Mercado Público e por ajudar diversos parentes vindos da colônia a se estabelecerem no local, esse informante-chave facilitou o acesso de um dos pesquisadores a essa rede familiar, apresentando e relacionando as ligações existentes entre seus membros.

Existem, no mínimo, outras três redes de parentescos como essa dentro do Mercado Público: há os permissionários vindos de Portugal que na sua grande maioria possuem bares, restaurantes e lancherias, além de padarias, e que ficam do lado de fora do mercado; há, também, uma família constituída de seis irmãs brasileiras de origem italiana, vindas do interior, que também possuem bancas no mercado; e ainda existe uma interligação entre pai, tio, filho e irmão de origem alemã que têm bancas no mercado.

Para Leone (1992), sendo a sucessão um ritual de transmissão de poder e do patrimônio entre duas gerações, no Mercado Público esse processo acontece de forma natural, sem planejamento. Um permissionário que herdou a banca do pai relatou que o processo "foi gradativo, o pai foi largando". A continuidade é um processo natural, como o permissionário que relatou que o pai "já era aposentado. Nós já trabalhávamos há quase 10 anos, quando ele se desligou da empresa e continuei eu". Para muitos dos permissionários "a idéia desde que comecei a trabalhar era, com o tempo, suceder o pai".

Porém, existem casos, segundo Leone (1992), em que o processo de transição ocorre de forma inesperada e repentina, como um permissionário que relatou que ao ter "câncer no intestino", seus filhos tiveram de assumir a banca. Uma permissionária que comanda a banca há oito anos, desde o falecimento do pai, diz que ele trabalhou até o último momento, quando morreu inesperadamente. Segundo ela, "o pai tinha o intuito de largar, aproveitar a vida", visto que ela e o seu irmão já administravam a banca.

Existem permissionários que, além de trabalharem com os filhos, já os tornaram sócios. A passagem das cotas da sociedade da banca para os filhos é descrita como um marco no processo sucessório. Contudo, nem sempre a posse das cotas significa ter o poder para administrar. Um dos permissionários, que há seis anos passou a ter as cotas, revela que: "não tava no meu nome, mas era eu que administrava, pois o processo sucessório foi gradual. Não foi nenhuma emergência, necessidade extrema. Quando me dei conta (...) foi acontecendo". Nesse caso, o processo sucessório foi uma situação natural (LEONE, 1992) em que o fundador conseguiu passar o comando da banca para o filho.

Há filhos que ainda trabalham com os pais e que querem continuar o negócio, como no caso em que o filho diz que "desde pequeno quis sempre continuar o negócio". Ele fala que "as cotas serão passadas daqui a cinco anos, quando o pai vai se aposentar". Mesmo prevendo cinco anos para assumir o negócio sozinho, declara que "não há planejamento", uma vez que "para continuar o negócio é importante ter interesse pelo negócio".

Foi igualmente constatado que os permissionários não estão preocupados com a organização da sua sucessão, pois além de não projetarem as etapas que Leone (1991) descreve que um processo sucessório percorre, não se importam em formalizar o futuro dos seus negócios.

Um dos permissionários, com 28 anos de Mercado Público, faz referência que o filho só vai assumir "quando eu parar" pois "ele vem para continuar, para começar". Entretanto, nem sempre o pai quer passar as cotas, como relatou o filho de outro permissionário, pois na sua opinião, o seu "pai passará as cota só quando morrer". Ele prevê que isso acontecerá daqui a 10 anos, e terá como fato marcante o "pai ficar impossibilitado de 
trabalhar". Como foi constatado, os permissionários das bancas do Mercado Público não se preocupam em planejar o processo sucessório, deixando que isso aconteça de forma natural ou por um processo inesperado. Segundo Scheffer (1995), muitas vezes, o processo sucessório não tem planejamento devido à recusa da idéia da morte e ao medo da perda do poder do sucedido.

Nesse sentido, a aposentadoria não é tomada como marco para parar, já que os permissionários não se sentem bem em ficar sem trabalho. Aposentar-se para eles é sinônimo de improdutividade, de tornar-se inútil e "virar" preguiçoso. Além do caráter utilitário, o trabalho se apresenta como um meio de estar integrado ao convívio diário. A resistência do pai em deixar a banca para se aposentar é um dos motivos que atrapalham a sucessão. Um permissionário, ao ser perguntado quando pretendia parar de trabalhar, respondeu: "um homem não pode parar de trabalhar; se ele pára, morre". Para ele, o processo sucessório significa "uma responsabilidade da luta diária de 14 horas de trabalho que vai ser distribuída".

Os filhos de permissionários cujos pais estando para se aposentar, ou mesmo aposentados, não querem deixar de freqüentar o Mercado Público afirmam que "o pai já se aposentou e não pensa em largar tão cedo, já que ele tem resistência em deixar a banca" ou que "ele até está para se aposentar, mas tenho certeza que em casa ele não vai ficar!"

Segundo Levinson (1977), apesar de repetidas promessas de se aposentar, a primeira geração recusa tanto a idéia de parar quanto de ter de delegar poder ao sucessor. Conforme Leone (1992), existe um verdadeiro apego sentimental do fundador ao seu negócio, porque ele não considera a empresa como um simples bem que pode deixar para os filhos após anos de muito sacrifício.

Além da falta de planejamento, não são feitas referências à profissionalização da administração das bancas do Mercado Público. Para Leone (1992), a forma utilizada ou aconselhada para resolver problemas referentes à sucessão tem sido a profissionalização da empresa familiar com a contratação de profissionais. Contudo, no Mercado Público de Porto Alegre, em nenhuma entrevista, houve menção à contratação de profissionais de fora da família para gerir o negócio.

\section{Trabalho e estudo}

Os filhos que têm curso superior e que vão trabalhar com os pais nas bancas vêem este período no mercado como temporário ou como de uma certa frustração. Marta se pudesse não continuaria no negócio do pai. Como afirma Lodi (1994), o comprometimento do fundador do negócio não é o mesmo da segunda geração que assume a empresa, pois muitos acabam optando pelo negócio por causa do dinheiro e pela obrigação. Da mesma forma que Marta, trabalham porque têm que trabalhar, não porque querem trabalhar.

Quanto à importância do estudo para continuar o negócio do pai, pais e filhos afirmam que no mercado "se aprende mesmo na prática, no dia-a-dia". Para os filhos "não tem muita necessidade de estudar para trabalhar aqui; o importante é se relacionar bem, falar bem com as pessoas". Ao mesmo tempo, os pais salientam a importância do estudo para que os filhos, no futuro, não necessitem continuar trabalhando no mercado. A fala de um permissionário ao comentar sobre os filhos prosseguirem seu negócio no mercado é a de que "a princípio, não; tem de estudar, conseguir uma coisa melhor para eles; eles vêm aqui gostam, mas eles têm de ter uma coisa melhor".

Embora declarem que os pais davam importância à educação formal, os filhos que continuaram no Mercado Público achavam que o pai não fazia questão que tivessem curso superior para administrar a banca. Um dos permissionários revelou que desejava que o seu filho se formasse, "tivesse título", e que por isso "cobrava colégio". Um dos filhos que ainda trabalha com o pai na banca conta que este continua insistindo na idéia de que "a única coisa que não tem como roubar de uma pessoa é o diploma". Outro permissionário ressaltou que foi incentivado a estudar "até o segundo grau, com certeza", mas que, depois, na graduação, "em virtude do curso (área da saúde) que escolhi, não". Os permissionários da primeira geração - como já foi dito, geralmente vindos do interior - não tiveram oportunidade de estudar. Como diz uma permissionária, "por falta de incentivo e de condições, eu não pude estudar; 12 km de distância para estudar". Em relação a suas filhas, revelou que 
"se não derem para o estudo, vão para o mercado; vão ter de continuar; o pai delas fez UFRGS, é lá que eu quero ver elas".

A aprendizagem do trabalho no mercado se dá através da observação e da prática. Ao trabalhar com o filho, conforme Grzybovski (2002), o pai procura socializar o sucessor em seu mundo, influenciando o filho a desenvolver traços e imagens semelhantes às suas formas de agir. O conhecimento tácito é transmitido de pai para filho. Existe uma ambigüidade entre a valorização e a desvalorização do trabalho manual frente à educação formal. Os permissionários da primeira geração justificam-se pelo pouco estudo em função das difíceis condições de sobrevivência; que mesmo em situações adversas tentaram estudar, parando diante da clara impossibilidade. Essa valorização do ensino é observada também pelo orgulho dos filhos dos permissionários que tiveram acesso à escola e à universidade. Mesmo considerando altas as mensalidades das universidades particulares, destacam como importante o fato de os filhos se sentirem bem e independentes.

Mesmo com curso superior, os filhos não fazem uso dos conhecimentos formais adquiridos fora do mercado e não inovam muito em relação à forma de administrar dos pais. Eles limitam-se a dar continuidade ao que vinha sendo realizado em termos administrativos na banca, uma vez que, como diz a sabedoria popular, "não se mexe em time que está ganhando". Segundo Leone (1992), os herdeiros adquirem conhecimentos indispensáveis à direção do negócio ao lado do pai, pois, geralmente, a preparação acontece na própria empresa, pela transmissão dos conhecimentos necessários. Os sucedidos não revelam muito interesse em procurar profissionais externos para assumir a direção do negócio. Todavia, estão preocupados em formar e treinar seus sucessores para assumir esses postos com conhecimento de causa; ou seja, de pai para filho, por muito tempo ainda.

Para Grzybovski (2002), o pai sucedido, quando se sente seguro de que o seu negócio terá continuidade, percebendo que serão adotados os mesmos fundamentos e cuidados na administração que vinham sendo empregados, reconhece o seu sucessor, independentemente de sexo, idade ou hereditariedade.

O trabalho no Mercado Público, além de ser duro, também se caracteriza por ser manual, pois nas bancas é preciso carregar produtos para o estoque e destes para a prateleira. Como não existe muito espaço para o armazenamento, é necessário receber diariamente as mercadorias, sendo inevitável estar sempre carregando caixas e sacos. O esforço físico e a sujeira envolvida nessa atividade são as justificativas apresentadas para o pequeno número de mulheres que trabalham no mercado; sendo esse trabalho considerado inadequado para elas.

\section{Trabalho no Mercado Público igual a castigo}

Para os homens, trabalhar com os pais no mercado parece uma opção mais interessante que o estudo. Tanto trabalhar como estudar pode ser um castigo quando eles têm de trabalhar por não irem bem nos estudos ou quando têm de estudar porque não querem trabalhar. Nesse ponto, existe um contraste, na medida em que, enquanto para o pai, trabalhar no mercado foi a possibilidade de se estabelecer financeiramente e tornar-se independente, para a segunda geração, trabalhar no mercado é um dever, uma obrigação; em alguns casos, um castigo.

Um filho de permissionário que está terminando seu curso superior revela que começou a trabalhar cedo, porque não gostava de estudar. Segundo ele "vim me criando nessa empresa" O pai, ao ver que ele ia mal na escola, propôs: "vem que tu vai ganhar tanto" Segundo esse filho, foi um erro, pois além de ser uma alternativa para não estudar, ele trabalhava pelo dinheiro. Além disso, o filho reclama que herdou de seu pai, sócios que ele não escolheu, tendo que dividir a administração da banca com pessoas que não eram conhecidas nem de sua confiança, mas fruto de relacionamentos advindos de uma convivência com o seu pai. Para ele, o trabalho do pai, que era calcado na paixão e numa visão empreendedora, permitiu que ele e sua irmã estudassem e tivessem uma formação técnica e gerencial adequadas à administração do negócio. Entretanto, apesar dessa formação técnica e gerencial, o filho continua administrando a banca tal como o pai administrava, isto é, "com a barriga no balcão". 
Para Amat (2000), uma das diferenças entre a primeira geração e os seus filhos é que, enquanto aquela é identificada como de empreendedores, estes apresentam perfis mais profissionalizados para a administração do negócio. Continuar administrando a banca "com a barriga no balcão", como o pai, pode ter sido a maneira encontrada pelo filho para identificar-se com ele.

\section{Independência financeira e proximidade afetiva}

Além do estudo, o fato de começar a ganhar dinheiro cedo é apontado como motivador para querer trabalhar. O filho de um permissionário, 27 anos, começou a trabalhar no mercado com 13 anos, sendo que há 10 anos tem carteira assinada. Relata que, diferentemente dele, suas duas irmãs, uma de 22 anos e outra de 25 anos, fazem faculdade, cursando biologia, e que só trabalham na banca durante as férias. Esse mesmo filho diz que continua no Mercado Público por causa das "amizades que tu faz aqui", pois "faz 15 anos; já é uma vida aqui dentro. Bem ou mal é a minha segunda família".

Outro ponto importante sobre a questão da continuidade da empresa familiar no mercado é que muitos filhos começaram cedo, visitando seus pais nas bancas. Para Grzybovski (2002), muitos vêem no seu próprio negócio uma forma de poderem compartilhar o tempo com filhos, o cônjuge e as demais atividades de um lar. Um filho de permissionário revela que "às vezes visitava o pai, gostava muito, para ficar perto do pai; gostava de trabalhar e ajudar, ser útil". Outro permissionário revelou que, como o pai ficava muito tempo fora de casa, "sentia falta do pai no ar" e por isso gostava de ver o pai na banca.

Erikson (1986) explica que a criança desde muito pequena se defronta com numerosas oportunidades de se identificar com hábitos e ocupações característicos dos adultos que a cercam. As etapas de vida passadas no mundo adulto repercutem no mundo infantil, da mesma forma que as crises e as fases de vida dos filhos influenciam e interagem com os estágios da vida de seus pais.

Aliado ao fato de começarem a trabalhar, ainda, jovens, de preferirem o trabalho ao estudo, de estarem junto com o pai, existe também um sentimento de que continuar trabalhando no negócio da família é seguir um destino já traçado, uma missão. Ao mesmo tempo em que gostam, têm prazer no que fazem e estão identificados com o negócio, parecem demonstrar certa frustração porque não tiveram outra opção que não fosse continuar o negócio da família.

Ao mesmo tempo em que alguns pais afirmam que o futuro dos filhos "é o mercado, aí fora fazer o quê?" referindo-se ao mercado de trabalho -, dizendo que estes vão ter de "engolir" o Mercado Público "goela abaixo", existem pais que nunca quiseram levar os filhos para visitá-los no mercado; muito menos querem que eles trabalhem ali. Esses pais que não querem que os filhos trabalhem no Mercado Público, geralmente, reconhecem em nossa cultura uma desvalorização social do trabalho manual. Esses permissionários preferem que seus filhos estudem (DURHAM, 1984) e tenham uma "profissão", já que para eles o trabalho que não é manual é mais "fácil" e valorizado, sobremaneira pela sociedade.

Um dos permissionários que tem filho adolescente relatou que "traz os filhos desde pequeno, porque se eles não têm 12 horas de trabalho desde pequeno, até gostam do mercado, mas não amam o mercado". Para ele, muitos filhos de permissionários não seguem o trabalho na banca porque "é muita hora de trabalho".

Outro permissionário, ao falar sobre a possibilidade da filha de 15 anos, que cursa o segundo grau, trabalhar com ele no mercado, considerou isso "pouco provável, prefiro que ela faça faculdade; se depender de mim, não, eu não quero". Quanto ao filho de 12 anos, disse que "ele até pode querer, mas eu não quero". Apesar de ele não querer, observa que o filho "quer vir trabalhar e vem, aos sábados, almoçar, botar preço, limpar".

Há também o caso do permissionário que ao ser perguntado por que somente o filho está trabalhando na banca, e as filhas não, respondeu que "há 10 e há 20 anos atrás, mulher para trabalhar aqui era difícil, a gurizada só dizia besteira". Nesse caso, as filhas deveriam estudar "que era melhor". Hoje, contudo, ele entende que as filhas "poderiam trabalhar no mercado, pois é outro ambiente". Mesmo assim, diz que a filha é dentista, tem consultório e não gostaria de sucedê-lo, visto que, na sua opinião, está "melhor que eu". Boscarin (2001) escreve que, apesar dos avanços ocorridos nas últimas décadas em relação às mulheres que ocupam cargos 
gerenciais nas empresas, o preconceito e a discriminação ainda são fortes barreiras à presença feminina nos negócios.

\section{Relações e conflitos}

Grande parte dos conflitos entre os permissionários e os seus filhos tem origem na visão diferenciada que uns e outros têm sobre o negócio. Segundo estes, há muita dificuldade em implantar novas idéias. A filha de um permissionário reclama que gostaria de "modernizar, colocar a banca mais para frente, botar telentrega, computador". Para ela, como "na época dele dava certo, tem de continuar assim; o pai tem medo de mudar". Outro filho de permissionário diz que os conflitos estão relacionados à administração da banca, como "comprar ou não, vender agora ou não", pois, segundo ele, o "modo de pensar é diferente, pois somos de gerações diferentes".

Quanto à relação com os pais, a maioria dos filhos a classificava como "boa", "muito boa", "excelente" ou "tranqüila". Alguns reclamaram que, como o pai trabalhava demais, não tiveram muito contato com ele durante a infância, somente quando iam visitá-lo na banca.

Ainda sobre a relação com os pais, alguns filhos a descreveram como complicada, sem diálogo e muito estressante, tanto no âmbito da banca quanto no familiar. Nos negócios, os filhos caracterizavam seus pais como "cabeça dura", "contra o novo e todo tipo de mudança", "adepto ao tradicional", que precisa de "controle o tempo todo", sendo o "dono da razão". No âmbito familiar, rotulavam como "autoritários" e "sem diálogo". Para ilustrar o conflito, um dos filhos citou o fato dele ser simpatizante de um determinado partido político e seu pai odiar esse partido e que isso era motivo para não conversarem. Os filhos apontam a baixa escolaridade de seus pais e o fato de que estes tiveram de trabalhar muito para construir o que eles têm como a causa desse tipo de comportamento.

Durante o processo sucessório, um dos permissionários mencionou que a relação com o seu pai teria mudado no sentido de não mais se restringir às emoções inerentes ao contexto familiar, mas também agregar aspectos atinentes ao mundo do trabalho, ou seja: "a relação [...] fica muito mais profissional do que a afetiva". Uma das filhas classificou sua relação com a mãe de "comercial", na banca, onde a mãe é a "patroa".

Os filhos apontam as seguintes qualidades de seus pais: trabalhador, honesto, sincero, muito bom, responsável, paciente, persistente, bem humorado, dinâmico, extremamente competente, carismático, visionário, tem visão, tino para o comércio, sabe lidar com o cliente. Quanto aos defeitos, apontam: nervoso, impaciente, imediatista, "tudo para ontem", "cabeçudo", desatualizado, "não tem visão do futuro", "não modernizar a banca", "dedicar mais tempo para ele mesmo", "pouco tempo para o filho", teimoso, "pensamento dele é muito certo", desconfiado e "pé atrás".

No que concerne ao futuro, os filhos dos permissionários, na sua maioria, querem montar outro negócio e deixar de trabalhar a médio e longo prazo no negócio da família. A perspectiva de sucesso referida por eles, em nível salarial, é ganhar igual ou mais do que ganham na banca. Em termos de satisfação pessoal, acreditam que não vai ser tão bom quanto trabalhar no mercado.

Os principais aspectos facilitadores citados pelos permissionários ao herdar uma empresa familiar foram: "tradição prontinha", "é só aprimorar o que já foi feito", "seqüência", "já tá tudo pronto", "manha do negócio", "mão beijada", "bom relacionamento", "aprendizado", "negócio montado sob olhos de quem está aqui dentro", "tranqüilidade", "já tá trabalhado", "mais cômodo", "jogo aberto", "não precisa nada no papel" e "confiança". Para Donnelley (1976), uma das vantagens que uma empresa familiar apresenta é sua identidade reforçada e a tradição familiar presentes no negócio.

Por seu turno, as dificuldades apontadas foram: "negócio com dívidas", "abrir mão da minha área [de trabalho]", "quatro anos de faculdade" [estudo], "dependência da família", "vícios", "horário e regime de trabalho", "tem muito palpite", "não tem um que mande", "prisão" e "pouco lazer". Alguns permissionários, entretanto, disseram não ver nenhuma dificuldade. 
Donnelley (1976) aponta os conflitos entre os interesses da família e os da empresa como um dos maiores obstáculos que esse tipo de empreendimento precisa vencer.

\section{Enfim, as criações nas passarelas: considerações finais}

Ao resgatar a trajetória de vida, profissional e pessoal, dos permissionários e de suas famílias, descobriu-se a existência de uma extensa rede de parentesco. Na sua grande maioria, os permissionários da primeira geração saíram da colônia para a cidade em busca de melhores condições de vida. Tinham como referência parentes próximos ou distantes que lhes davam oportunidade de começar a trabalhar no Mercado Público e em cujas casas eram acolhidos até que conseguissem se estabelecer na cidade.

Quanto ao processo sucessório, foi constatado que existem bancas em diferentes estágios do processo sucessório. Há bancas só com a primeira geração trabalhando, porque os filhos ainda são pequenos ou porque não quiseram continuar no negócio. Há bancas em que a primeira e a segunda geração trabalham juntas; sendo que em algumas destas os filhos já têm cotas do negócio, enquanto em outras, ainda não. Existem ainda bancas nas quais a primeira geração já passou as cotas e a administração da banca para os filhos, e a primeira geração não está mais no Mercado Público. Há bancas em que só a segunda geração trabalha, seja porque ainda não tem filhos, porque os filhos são pequenos ou mesmo porque estes não querem continuar o negócio familiar. Existem casos em que a segunda geração trabalha com a terceira geração; sem contar que existe uma banca onde a terceira geração comanda sozinha o negócio.

Os resultados evidenciam ainda que os permissionários, além de não prepararem seus filhos, também não se preparam para desligar-se da banca, pois têm resistência em abrir mão da autoridade e delegar aos filhos a continuação do negócio. Dessa forma, não há planejamento do processo sucessório, constatando-se que este ocorre de forma natural ou repentina (acidente que impossibilite o permissionário de trabalhar). A passagem das cotas do negócio do pai para o filho é um momento marcante nessa transição.

No que se refere à escolaridade, enquanto a primeira geração, em sua maioria, tem o primeiro grau, muitos filhos da segunda geração presente no Mercado Público têm segundo grau ou curso superior. Nesse sentido, a educação pode ser vista como uma forma simbólica de ascensão social, da mesma forma como a migração da colônia para a cidade e o conseqüente acesso a bens e a imóveis.

Dessa forma, para alguns filhos de permissionários, concluir um curso superior e seguir uma carreira fora do Mercado Público pode significar que estão ascendendo socialmente e "tendo melhores condições de vida", como almejado tanto pelos imigrantes que chegaram da Europa quanto pelos "colonos" vindos do interior. Portanto, continuar no negócio do pai, ainda que para alguns resulte em maior êxito financeiro e econômico, pode significar que o seu trabalho não seja tão valorizado, mesmo com uma graduação. Nesses casos, os permissionários acreditam que fora do mercado é que se pode exercer uma profissão - como se a atividade que exercem não o fosse - e que o trabalho intelectual é considerado muito menos árduo do que o trabalho manual realizado no Mercado Público.

Geralmente os pais querem que as filhas estudem e que não trabalhem no mercado, ao mesmo tempo que se mostram ambivalentes quanto à possibilidade de os filhos seguirem na sua banca. Os filhos começam a trabalhar na banca dos pais ainda adolescentes, muitas vezes, por castigo, em virtude do baixo desempenho escolar. Entre trabalhar ou estudar, os filhos preferem o negócio do pai.

As relações de família e organizacionais entre os permissionários e seus prováveis sucessores começam muito cedo, pois os filhos, desde pequenos, costumam visitar os pais nas bancas, onde brincam, trabalham e, principalmente, ficam ao lado destes. A ausência paterna em casa é a principal reclamação por parte dos filhos; e, na banca, os maiores conflitos entre os membros da família são causados pela visão diferenciada em relação ao negócio.

Foi observado ainda que os desejos inconscientes do permissionário, a que se refere Levinson (1977), para que sua obra (negócio) se perpetue, podem ser transmitidos a seus filhos. Por conseguinte, seguir o negócio do pai 
pode significar um mandato, uma sina, um fardo que o filho carrega sem ter consciência e, conseqüentemente, sem poder pensar sobre as razões que o levam a isso. Aqui, pode-se concluir que o ambiente no qual a criança foi socializada sempre privilegiou o trabalho como valor relevante e, assim, é essa exemplaridade que muitos filhos optam por seguir, ou melhor, com a qual buscam se identificar.

Como pano de fundo, ao "desfilar" esses resultados, é possível associar a "confecção" dos resultados da pesquisa sobre o Mercado Público de Porto Alegre com a imagem de uma aldeia indígena. As famílias de origem italiana, portuguesa e alemã, entre outras, seriam as tribos dessa aldeia. Aldeia essa que tem a função de abrigar e dar suporte às famílias vindas de fora. Por ser o primeiro local de acesso para muitas dessas famílias, essa aldeia (Mercado Público) seria caracterizada como um local de transição para que mais tarde os filhos e/ou netos desses primeiros habitantes pudessem se estabelecer em outras atividades e ter acesso a outras oportunidades. É como se fosse o que Winnicott (1990) chama de fenômeno de transição, em que o Mercado Público serviria de ponte entre a situação de vida anterior e o futuro, pois ao acolher, forneceria condições de crescimento e desenvolvimento.

Muitos do permissionários mencionaram a segurança que o mercado oferece para trabalhar e ganhar dinheiro. Alguns no entanto, declararam que ele não oferece futuro. Nesse sentido, a própria atividade do mercado, o comércio, apresenta um caráter imediatista (compra e venda). Tal como o próprio Mercado Público, essa atividade é o presente que permite a sobrevivência, assegurando o sustento diário da família. Por não precisar postergar frustrações, visto que a compra e venda traz resultados mais instantâneos que o investimento no futuro, como o curso superior, a possibilidade de continuar trabalhando no mercado implica viver o presente, herdado do passado, tal como ele se mostra.

\section{Referências bibliográficas}

AMAT, J. M. La continuidad de la empresa familiar. Barcelona: Gestión, 2000.

BARBIERI, E. M. A batalha das herdeiras na empresa familiar. Porto Alegre: Sagra, 1997.

BERNHOEFT, R. Empresa familiar: sucessão profissionalizada ou sobrevivência comprometida. São Paulo: Ibecon, 1987.

BOSCARIN, R. et al. Mulher, conhecimento e gestão empresarial: um estudo nas empresas familiares. In: Enanpad, 25., 2001, Campinas. Anais... [S.I.], 2001. CD-ROM.

CARRÃO, A. Empresa Familiar: Riscos e oportunidades. In: Enanpad, 21., 1997. Rio das Pedras. Anais... [S.I.], 1997. CD-ROM.

CAVEDON, N. R. "Pode chegar, freguês": a cultura organizacional do Mercado Público de Porto Alegre. In: Enanpad, 26., 2002, Salvador. Anais... [S.I.], 2002. CD-ROM.

DONNELEY, R. G. A empresa familiar. Biblioteca Harvard de Administração de Empresas. São Paulo: Abril-Tec, 1976.

DURHAN, E. A caminho da cidade: a vida rural e a migração para São Paulo. São Paulo: Perspectiva, 1984.

ERIKSON, E. Infância e sociedade. Rio de Janeiro: Zahar, 1986.

FLORIANI, O.; RODRIGUES, L. Sucessão empresarial: processo sucessório em empresas familiares. In: Egepe 1., 2000, Londrina. Anais... Londrina, 2000. p. 299-312.

GRAM KOW, F.; CAVEDON, N. R. As bancas de especiarias do Mercado Público de Porto Alegre e suas estratégias. Organizações e Sociedade, Salvador, v.8, n.22, set./dez. 2001.

GRZYBOVSKI, D. 0 administrador na empresa familiar: uma abordagem comportamental. Passo Fundo: UPF, 2002.

LANZANA, A.; COSTANZI, R. As empresas familiares brasileiras diante do atual panorama econômico mundial. In: MARTINS, I. G.; M ENEZES, P. L.;BERNHOEFT, R. (Org.). Empresas familiares brasileiras: perfil e perspectivas. São Paulo: Negócio, 1999.

LEONE, N. A sucessão não é tabu para os dirigentes da PME. In: Enanpad, 1991, Belo Horizonte. Anais... Belo Horizonte, 1991. p $243-247$. . A sucessão em PME comercial na região de João Pessoa. Revista de Administração, São Paulo, v.27, n.3, p.84-91, jul./set.1992. Sucessão: como transformar o duelo em dueto. Revista de Administração - Rausp, São Paulo, 1996. As especificidades das pequenas e médias empresas. Revista de Administração, São Paulo, v.34, n.2, p.91-94, abr./jun.1999. . 0 Saara não é um deserto: o processo sucessório de suas empresas é repleto de conhecimentos. In: Enanpad, 26., 2002, Salvador. Änais... [S.I.], 2002. CD-ROM. 
LEVINSON, H. Os conflitos que infestam as empresas de família. Biblioteca Harvard de Administração de Empresas. São Paulo: Abril-Tec, 1977.

LODI, J.O fortalecimento da empresa familiar. São Paulo: Atlas, 1986.

. A empresa familiar. São Paulo: Pioneira, 1993.

. A ética na empresa familiar. São Paulo: Pioneira, 1994.

LONGENECKER, J et al. Administração de pequenas empresas. São Paulo: Makron, 1997.

MACIEL, M. Considerações sobre gaúchos e colonos. In: BAQUERO, M. et al. Diversidade étnica e identidade gaúcha. Santa Cruz do Sul: Unisc, 1994.

MORGAN, G. Imagens da organização. São Paulo: Atlas, 1996.

OLIVEN, R. A parte e o todo: a diversidade cultural no Brasil-Nação. Petrópolis: Vozes, 1992.

SCHEFFER, A. Sucessão em empresas familiares: dificuldades e ações preventivas. 1993. Dissertação (M estrado em Administração) - PPGA, UFRGS, Porto Alegre.

Fatores dificultantes e facilitadores ao processo de sucessão familiar. Revista de Administração, São Paulo, v.30, n.3, jul./set.1995.

TANAAMI, K.M. 0 que vai mudar no planejamento da sucessão familiar: herança sem briga. Exame, 26 jun. 2002.

TONDO, C. Terapia familiar: bases, caminhos percorridos e perspectivas. In: SOUZA, Y. et al (Org.). Família, organizações e aprendizagem: ensaios temáticos em Psicologia. Porto Alegre: PUCRS, 1998.

. Empresas familiares: ciclos de vida e processos de liderança. 1999. Tese (Doutorado em Psicologia) - PUCRS, Porto Alegre.

VIDIGAL, A. As origens da empresa familiar no Brasil. In: MARTINS, I. G.; MENEZES, P. L.; BERNHOEFT, R. (Org.). Empresas familiares brasileiras: perfil e perspectivas. São Paulo: Negócio, 1999.

. A sobrevivência da empresa familiar no Brasil. Revista de Administração, São Paulo, v.35, n.2, p.66-71, abr./jun. 2000.

WINNICOTT, D. 0 ambiente e os processos de maturação: estudos sobre a teoria do desenvolvimento emocional. Porto Alegre: Artes Médicas, 1990.

WOORTM ANN, E. Herdeiros, parentes e compadres: colonos do Sul e sitiantes do Nordeste. Brasília: UNB; São Paulo: Hucitec, 1995. 